\title{
Intravenous Leiomyomatosis of the Uterus with Continuous Extension into the Pulmonary Artery
}

\author{
Nobuharu Akatsuka, M.D., Kazuyuki Tokunaga, M.D., \\ Takaaki Isshiki, M.D., Ken-ichi Asano, M.D., \\ Haruo Funaki, M.D., Masahiko Mizuno, M.D., \\ Takashi Kawana, M.D., and Hiromu Aoyama, M.D.
}

SUMmaRY

A 56-year-old woman presented with an intracardiac tumor, as shown by two-dimensional echocardiography. Surgical treatment, undertaken in two stages, revealed a tumor which arose in the uterus, passed through both ovarian veins, the inferior vena cava, the right atrium and ventricle, and the pulmonary trunk, and extended to both pulmonary arteries. The upper portion of the tumor was removed in the first surgical operation, and the remaining tumor was removed during a second operation 1 year later. Both specimens were identical in appearance, and a pathohistological diagnosis of benign leiomyoma was made.

\section{Additional Indexing Words:}

Benign intracardiac tumor Echocardiography Surgical operation Uterine myoma

GINCE the first report by Knauer in $1903,{ }^{11}$ intravenous leiomyomatosis has Deen reported infrequently in the literature. The tumor is characterized by the extension of smooth muscle tumors arising from the uterus into venous channels. ${ }^{2)}$ The histology of the tumor is benign. Among the cases reported previously, the tumors have only reached as far as the right ventricle. We describe a patient with intravenous leiomyomatosis which arose from the uterus and grew uninterrupted to both pulmonary arteries. The tumor was successfully removed in a two-stage surgical operation and was histologically benign.

From the Departments of Internal Medicine, Cardiac Surgery, Gynecology and Pathology, Faculty of Medicine, University of Tokyo, Tokyo.

Address for reprint: Nobuharu Akatsuka, M.D., First Department of Internal Medicine, Faculty of Medicine, University of Tokyo, 7-3-1 Hongo, Bunkyo-ku, Tokyo 113, Japan.

Received for publication August 18, 1983. 


\section{CAse Report}

A 56-year-old woman, gravida 2, para 2, visited the University of Tokyo Hospital in November, 1980, complaining of attacks of shortness of breath and cardiac murmur. In 1975, she had a short attack of weakness in the legs while walking on a street. In 1979, she experienced palpitation and visited a doctor, who suspected cardiac neurosis. In June, 1980, she had shortness of breath, and in July, she experienced nocturnal dyspneic attacks which led to orthopnea. These symptoms disappeared with the administration of digitalis. However, she occasionally had sensations of choking which persisted for a very short duration. In September, 1980, she was found to have a cardiac murmur. She had no symptoms of gynecological disorder.

The patient was active and alert. Blood pressure was $110 / 84 \mathrm{mmHg}$ and the heart rate was 88 beats/min and regular. The first and second heart sounds were normal; the third heart sound was audible in the apical region, and a grade $3 / 6$ systolic murmur of the ejection type was audible over the third intercostal space on the left parasternal line. The intensity and quality of the murmur changed posturally and with time. The lungs were clear. The liver was palpated $1.5 \mathrm{~cm}$ below the right costal margin. There was no pitting edema.

Laboratory findings were as follows: the erythrocyte sedimentation rate (ESR) was $1 \mathrm{~mm} /$ hour; RBC was $544 \times 10^{4} / \mathrm{mm}^{3} ; \mathrm{Hb} 17.0 \mathrm{~g} / \mathrm{dl}$; Hct $49.8 \%$. The WBC count was $6200 / \mathrm{mm}^{3}$ with a normal differential count. The platelet count was $2.9 \times 10^{4}$. Blood chemistry was normal. CRP and RA were negative. PSP was 23\% (15 min) and 70\% (2 hours). A chest X-ray showed generalized cardiomegaly with a CTR of $60 \%$. There were no signs of pulmonary congestion or tumor shadow. The electrocardiogram showed a normal sinus rhythm, and a tendency of low voltage of QRS complexes in all leads. The M-mode and two-dimensional echocardiograms disclosed masses in the right atrium prolapsing into the right ventricle (Fig. 1). The tumor appeared to be multi-lobulated, moving to and fro according to the phase of cardiac cycle, and tangling with each other. The inferior vena cava could not be fully visualized. A tentative diagnosis of right atrial myxoma, prolapsing into the right ventricle, was made. Because the tumor was considered fragile, cardiac catheterization was not performed. A pulmonary perfusion scintigram showed no abnormal perfusion defects.

On December 1, 1980, the patient was operated on under extracorporeal circulation. When the right atrium was opened, smooth finger-like grayish-yellow tumor masses were found to occupy most of the right atrial cavity (Fig. 2). The tumor extended into the right ventricle as well as into 


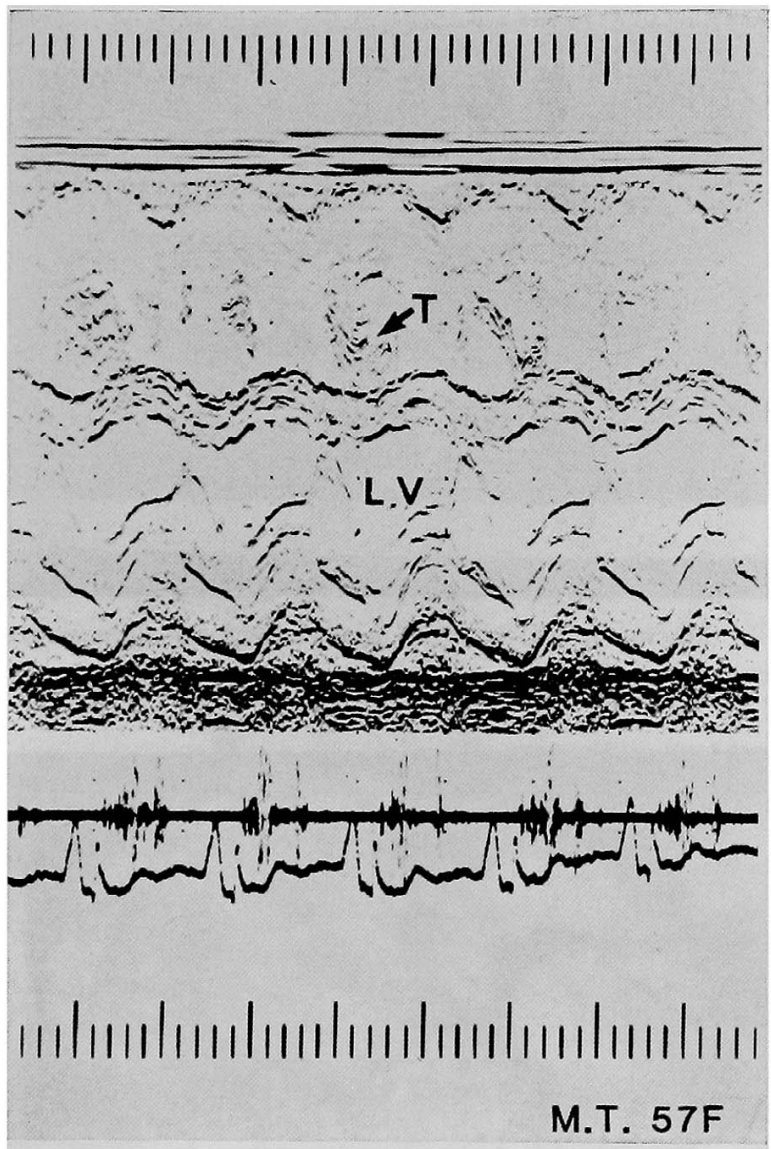

Fig. 1. M-mode echocardiogram of intravenous leiomyomatosis: arrow shows the tumor in the right ventricular cavity. $T=$ tumor; $L V=$ left ventricle.

the inferior vena cava. One tumor rod extended into the pulmonary trunk, and further into both the left and right pulmonary arteries.

A solid rod-like tumor and a cystic tumor containing blood came up through the inferior vena cava. The tumor did not adhere to the right atrium or to the right ventricle. However, it did adhere to the pulmonary trunk and to the right and left pulmonary arteries in small areas. The tumor toward the pulmonary artery was removed through a right ventriculotomy. However, neither distal end of the tumor toward the right and left pulmonary arteries could be removed because they were fixed tightly to the pulmonary arterial wall. An attempt was made to remove the tumors toward the inferior vena cava by pulling, but they were eventually cut about $10 \mathrm{~cm}$ distal to the right atrium. Histological examination revealed smooth muscle cells in the tumor, and a diagnosis of intravenous leiomyomatosis was made. The 


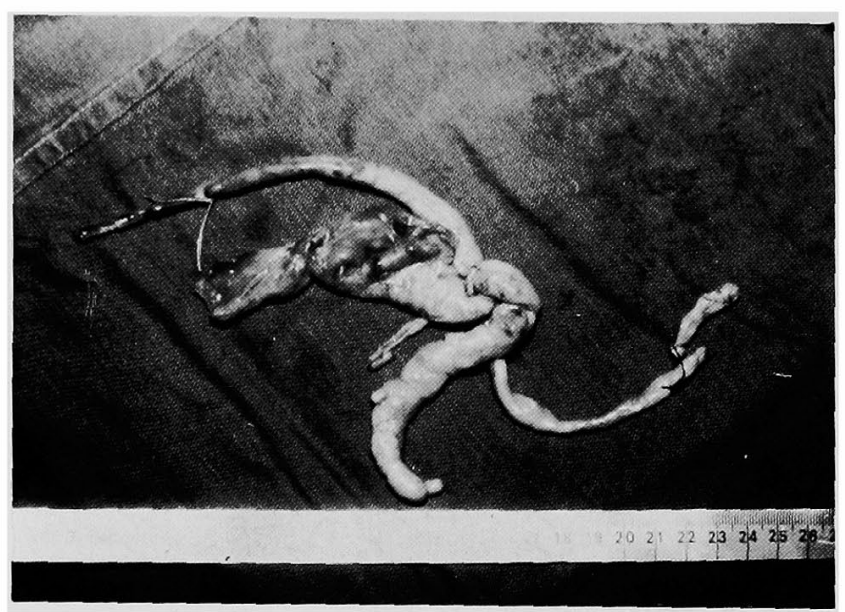

Fig. 2. Macroscopic view of the tumor taken from right cardiac cavity, inferior vena cava and pulmonary arteries.

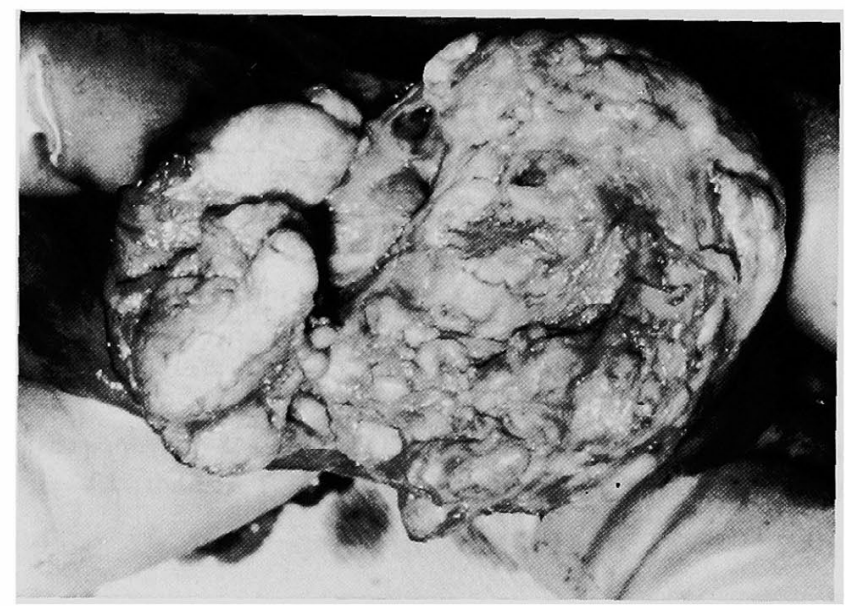

Fig. 3. Sectioned view of uterine myoma.

literature on intravenous leiomyomatosis suggests a probable uterine origin for the tumor, so the patient underwent a second surgical operation in January, 1982 to eradicate the residual tumor. A total hysterectomy combined with bilateral salpingo-oophorectomy was done, although the gynecological examination could not clearly detect tumor masses in the uterus or in the adnexa. The uterus was slightly enlarged and peculiar collateral vessels were remarkably well developed on the surface of the uterus and adnexa. The surfaces of the uterus, adnexa, and ligaments were bosselated, and many nodules, some of which were as large as a thumb tip, were palpated. The external surface of these nodules was soft and smooth. Upon sectioning the posterior wall of the uterus, innumerable white-gray, translucent, worm-like polypoid masses mea- 


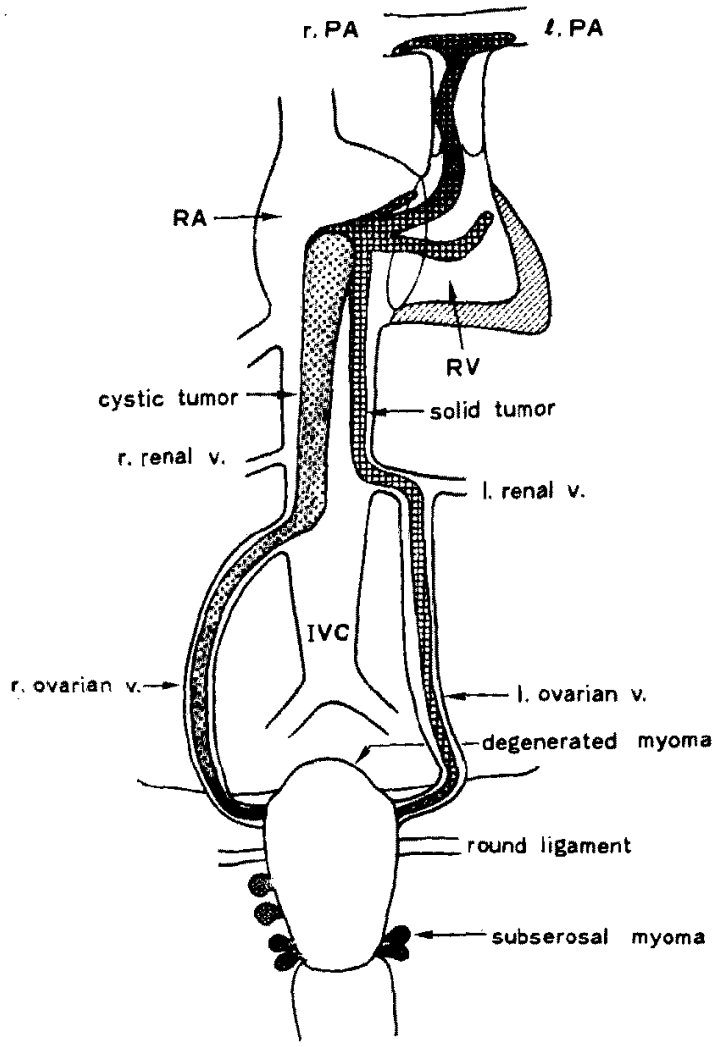

Fig. 4. Schematic drawing of the course of intravenous leiomyomatosis.

suring from $2 \mathrm{~mm}$ to $2 \mathrm{~cm}$ blossomed from the cut surface (Fig. 3). Some polypoid or worm-like extensions of the tumor protruded into the intraligamental uterine veins, and one extension was found on each side of the ovarian vein (Fig. 4). At the proximal ends of the tumors extracted from the ovarian veins, the suture materials, which had been left at the time of the first operation, were found.

Sections of myometrium showed intramural and subserosal multiple benign leiomyomas, which were composed of interlacing bundles of smooth muscle. Smooth muscle cells were generally small with oval to spindle-shaped nuclei and indistinct cytoplasmic margins. There were numerous blood vessels in many of these tumor nodules, unlike the usual type of uterine leiomyoma. No histologic features of malignancy were demonstrated. Although most of the polypoid tumors in the uterus were present within the intrauterine veins, many of these tumors were also found in channels lined with endothelium. Many tiny nodules, considered to be smooth muscle cell hyperplasia, were formed by proliferation of the media or adventitia of the intrauterine vein walls (Fig. 5). 


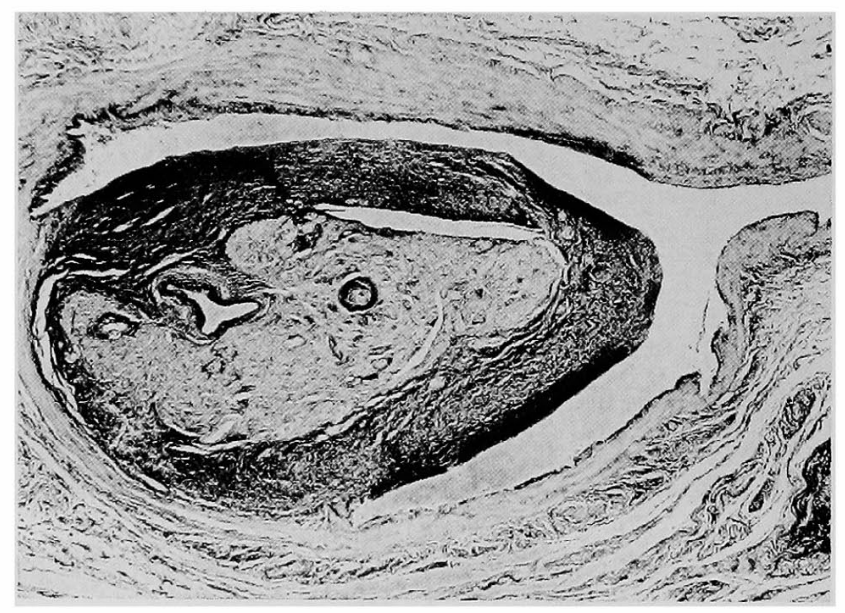

Fig. 5. Development of an intravenous leiomyoma showing origin from the intrauterine small vein wall with proliferating smooth muscle cells bulging into the venous lumen. Numerous blood vessels are seen in the leiomyoma. (Elastica van Gieson stain; $\times 40$ )

The postoperative course of the patient was uneventful. The platelet count returned to normal after the first surgical operation.

\section{Discussion}

Intravenous leiomyomatosis, a term first used by Marshall and Morris in $1959,{ }^{31}$ may be defined as the extension into venous channels of histologically benign smooth muscle tumors arising either from a uterine myoma or from the walls of the vessel itself. ${ }^{2)}$ As seen in this case, a peculiar pattern of venous engorgement may occasionally be seen macroscopically over the external surface of the uterus. The intravenous extensions are glistening gray or yellowish white, usually polypoid or plexiform, measuring from fine threadlike structures to pencil-sized, or occasionally large tubular casts $2-3 \mathrm{~cm}$ in diameter. The parauterine extensions may be worm-like, elastic, soft, almost mucoid structures protruding from the dilated veins. ${ }^{2)}$ There are 9 reported cases in which intravenous leiomyomatosis reached the heart (Table). ${ }^{4)-12}$ ) All cases were females ranging from 28 to 52 years old. Seven cases had uterine myomas and underwent hysterectomy several years prior to the detec-

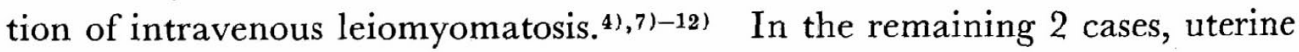
myoma and intravenous leiomyomatosis were found at autopsy. ${ }^{51,6)}$ The present case is the first proven case in which the tumor arising from the uterus extended continuously to the right and left pulmonary arteries and was removed intentionally almost in its entirety. Another peculiar aspect of this 
Table I. Summary of Reported Cases of Intravenous Leiomyomatosis Which Reached the Right Cardiac Cavity or Further

\begin{tabular}{|c|c|c|c|c|c|c|c|c|c|}
\hline \multirow{2}{*}{ No. } & \multirow{2}{*}{ Sex } & \multirow{2}{*}{$\begin{array}{l}\text { Age } \\
\text { (y) }\end{array}$} & \multirow{2}{*}{ Myoma uteri } & \multicolumn{3}{|c|}{$\begin{array}{c}\text { Confirmed intravenous } \\
\text { leiomyomatosis }\end{array}$} & \multicolumn{2}{|c|}{ Reference reported } & \multirow{2}{*}{ Outcome } \\
\hline & & & & from & to & method & author & year & \\
\hline 1. & $\mathrm{~F}$ & 43 & $\begin{array}{l}\text { myomectomy } 5 \\
\text { times in } 15 \text { years } \\
\text { died at total } \\
\text { hysterectomy }\end{array}$ & $\begin{array}{l}\text { hypo- } \\
\text { gastric } \\
\text { vein }\end{array}$ & RA & autopsy & Dürck & 1907 & $\begin{array}{l}\text { died at } \\
\text { hysterectomy }\end{array}$ \\
\hline 2 . & $\mathbf{F}$ & - & $\begin{array}{l}\text { myomatous } \\
\text { uterine tumor }\end{array}$ & uterus & RA & autopsy & Hoermann & 1907 & died \\
\hline 3. & $\mathbf{F}$ & 47 & + & uterus & RV & autopsy & Petrow & 1970 & died \\
\hline 4. & $\mathbf{F}$ & 32 & $\begin{array}{l}\text { hysterectomy \& } \\
\text { oophorectomy } \\
4 \text { years before }\end{array}$ & $\begin{array}{l}\text { iliac } \\
\text { vein }\end{array}$ & RV & surgery & Kaku & 1977 & alive \\
\hline 5. & $\mathbf{F}$ & 41 & $\begin{array}{l}\text { hysterectomy } \\
1 \text { year before }\end{array}$ & $\begin{array}{l}\text { iliac } \\
\text { vein }\end{array}$ & RV & surgery & Kono & 1978 & alive \\
\hline 6. & $\mathbf{F}$ & 42 & $\begin{array}{l}\text { hysterectomy \& } \\
\text { salpingo- } \\
\text { oophorectomy } \\
2 \text { years before }\end{array}$ & IVG & RV & surgery & Tierney & 1980 & alive \\
\hline 7. & F & 46 & $\begin{array}{l}\text { hysterectomy \& } \\
\text { salpingo- } \\
\text { oophorectomy } \\
2.5 \text { years before }\end{array}$ & $\begin{array}{l}\text { iliac } \\
\text { vein }\end{array}$ & RA & surgery & Timmis & 1980 & alive \\
\hline 8. & $\mathbf{F}$ & 28 & $\begin{array}{l}\text { hysterectomy \& } \\
\text { oophorectomy }\end{array}$ & $\begin{array}{l}\text { pelvic } \\
\text { veins }\end{array}$ & RA & $\begin{array}{l}\text { surgery } \\
\& \\
\text { autopy }\end{array}$ & Nili & 1982 & $\begin{array}{l}\text { died at } \\
\text { cardiac } \\
\text { surgery }\end{array}$ \\
\hline 9. & $\mathbf{F}$ & 52 & $\begin{array}{l}\text { hysterectomy } \\
15 \text { years before }\end{array}$ & uterus & RV & surgery & Maurer & 1982 & alive \\
\hline 10. & F & 58 & + & uterus & PA & surgery & Akatsuka & $\begin{array}{l}\text { present } \\
\text { case }\end{array}$ & alive \\
\hline
\end{tabular}

case was that tumors arising from the uterus extended through both ovarian veins to the right atrium where they adhered to each other.

One of the tumors growing into the right atrium through the inferior vena cava and arising from the lateral aspects of the uterus was a large tubular cast containing fresh blood and some clots. Maurer and Nanda' ${ }^{12)}$ reported a case of an intracardiac leiomyoma visualized by real-time two-dimensional echocardiography. They also visualized a mass in the inferior vena cava by the same technique. One of the reasons we were unable to detect these tumors in the inferior vena cava by echocardiogram might have been that the blood in the tubular tumor caused a pattern of echo-free space in the inferior vena cava, leading us to the false conclusion that there was no obstruction in the inferior vena cava. The microscopic findings in this case are consistent with reported cases.

The two theories of the histogenesis of intravenous leiomyomatosis con- 
sider two modes of origin. In 1902, Knauer reported 4 cases of intravenous leiomyomatosis. ${ }^{1)}$ The intravenous masses appeared to arise through proliferation of the smooth muscle of the media of the vein wall. On the other hand, Sitzenfrey ${ }^{13)}$ reported 3 cases in 1911 and believed that the tumor represented an extension into the vessels from adjacent extravascular myomatous tissue. Both investigators concluded that the tumor was histologically benign in all cases. Although the majority of histological findings show some connections of the tumor nodules to the media of the vein wall, as in the present case, and support Knauer's theory, the almost universal association of intravenous leiomyomatosis with uterine myomas tends not to totally dispel Sitzenfrey's thesis. Norris and Parmley ${ }^{14)}$ reviewed 14 cases and found evidence for both theories of origin. From the facts that the tumors develop during the period of genital activity and stabilize or regress after menopause, the influence of hormonal factors is suggested. Tierney ${ }^{91}$ presented an excellent discussion on the relationship between intravenous leiomyomatosis and hormonal factors after showing substantial quantities of cytoplasmic estradiol and progesterone receptors in the right atrial portion of the tumor of their case. The course is benign if the tumors are successfully removed. Although the case reported by $\mathrm{Kaku}$ et $\mathrm{al}^{7}$ ) showed metastases to the lungs, the patient is still alive about 9 years after surgical removal (personal communication).

Most of the reported cases of intravenous leiomyomatosis underwent total hysterectomy prior to the discovery of the intravenous leiomyomatosis. Although the appearance of intravenous leiomyomatosis in the uterus is unusual, these findings were obtained by re-examination of the uterus after the discovery of intravenous leiomyomatosis. Thus, more attention should be paid to the removed uterus at the time of hysterectomy in order not to leave residual tumors in veins. The ESR was normal in this case. In most cases of cardiac myxoma, the ESR is moderately accelerated; however, in intravenous leiomyomatosis the ESR is normal as far as shown in the reported cases. If one notices a tumor in the right heart by echocardiography in a middle-aged woman with normal ESR, intravenous leiomyomatosis should be included in the line of the differential diagnosis. Although removal of the tumor is the fundamental treatment, it appears that an antiestrogen agent might be recommended $^{9}$ ) if a large portion of the tumor cannot be removed.

\section{AGKNOWLEDGMENTS}

We thank Dr. A. Yamaguchi for referring the patient to our care. We also thank our colleagues in the Departments of Internal Medicine, Cardiac Surgery, Gynecology and Pathology: Dr. T. Saito, Dr. K. Tomomatsu, Dr. S. Hirose, Dr. A. Furuse, Dr. K. Yagyu, Dr. K. Tanaka, Dr. A. Kawagoe, Dr. R. Machinami and Dr. N. Mohri for their collaboration. 


\section{REFERENCES}

1. Knauer E: Beitrag zur Anatomie der Uterus-myome. Beitr z Geburtsh u Gynaek 1: 695, 1903

2. Baggish MS: Mesenchymal tumors of the uterus. Clin Obstet Gynecol 17: 51, 1974

3. Marshall JF, Morris DS: Intravenous leiomyomatosis of the uterus and pelvis. Case report. Ann Surg 149: 126, 1959

4. Dürck H: Ueber ein kontinvierlich durch die entere Hohlvene in das Herz vorwachsendes Fibromyom des Uterus. Mucnchen Mcd Wchnschr 54: 1154, 1907

5. Hoermann K: Ueber einen fall von myomatoesem uterustumor. Zentralbl Gynaekol 51: 1604, 1907

6. Petrow N, Rożynek M: Intravenoes wachsendes Uterusmyom. Zentralbl Allg Pathol 113: 24,1970

7. Kaku K, Kawashima $Y$, Danno M, et al: Resection of a leiomyosarcoma obstructing the tricuspid valve which originated in the internal iliac vein and occupied the IVC, RA and RV. J Jap Coll Angiol 17: 133, 1977 (in Japanese)

8. Kono N, Tanaka S, Shioiri $\mathrm{Y}$, et al: Removal of a giant leiomyoma of the vein propagating into the inferior vena cava, right atrium and right ventricle which led to tricuspid stenosis. J Japan Assoc Thorac Surg 26: 1113, 1978 (in Japanese)

9. Tierney WM, Ehrlich CE, Bailey JC, King RD, Roth LM, Wann LS: Intravenous leiomyomatosis of the uterus with extension into the heart. Am J Med 69: 471, 1980

10. Timmis AD, Smallpeice C, Davies AC, Macarthur AM, Gisher P, Jackson G: Intracardiac spread of intravenous leiomyomatosis with successful surgical excision. New Engl J Med 303: 1043,1980

11. Nili M, Liban E, Levy MJ: Tricuspid stenosis due to intravenous leiomyomatosis- a call for caution: case report and review of the literature. Texas Heart Inst J 9: 231, 1982

12. Maurer G, Nanda NC: Two-dimensional echocardiographic identification of intracardiac leiomyomatosis. Am Heart J 103: 915, 1982

13. Sitzenfrey A: Ueber Venenmyome des Uterus mit intravaskulaerem Wachstum. Ztschr Geburtsh u Gynaek 68: 1, 1911

14. Norris $H J$, Parmley $T$ : Mesenchymal tumors of the uterus $V$. intravenous leiomyomatosis: a clinical and pathologic study of 14 cases. Cancer 36: 2164, 1975 